\title{
A Novel Malonamide Periodic Mesoporous Organosilica (PMO) for Tuneable Ibuprofen Release
}

\author{
Sander Clerick ${ }^{1, *}$, Wannes Libbrecht ${ }^{1,2}$, Otto van den Bergh ${ }^{3}$, Els De Canck ${ }^{1}$, \\ Jeriffa De Clercq ${ }^{2}$, and Pascal Van Der Voort ${ }^{1, *}$ \\ ${ }^{1}$ Department of Inorganic and Physical Chemistry, Ghent University, Krijgslaan 281-S3, 9000 Gent, Belgium \\ ${ }^{2}$ Department of Industrial Technology and Construction, Industrial Catalysis and Adsorption Technology (INCAT), \\ Ghent University, Valentin Vaerwyckweg 1, 9000 Gent, Belgium \\ ${ }^{3}$ Department of Organic and Macromolecular Chemistry, Ghent University, Krijgslaan 281-S4, 9000 Gent, Belgium
}

\begin{abstract}
Incorporation of organic functionalities within porous materials is a very elegant manner to control the administration of therapeutic drugs. Delayed drug-release profile originates from weak and reversible interactions (e.g., electrostatic, hydrophobic-hydrophobic and $\mathrm{H}$-bonding interaction) between the modified carrier and the drug molecule. Two new silsesquioxane PMO precursors were synthesized in a quick and facile Schotten-Baumann reaction of (3-aminopropyltriethoxy)silane and (N-methyl-3-aminopropyltrimethoxy)-silane with malonylchloride, respectively. Based on these bis(3-(triethoxysilyl)propyl)malonamide (MA) and N,N-dimethyl-N,Nbis(3-(triethoxysilyl)propyl)malonamide (mMA) precursors, an extensive range of 2D hexagonal PMOs with high functional loading was obtained by the co-condensation with tetraethyl orthosilicate (TEOS) in a typical PMO synthesis (acidic medium, P123, $\mathrm{KCl}$ ). The materials showed good ordering up to $20 \mathrm{~mol} \%$ of functional loading, a large surface area (up to $550 \mathrm{~m}^{2} / \mathrm{g}$ ) and wide pores $(\sim 7 \mathrm{~nm})$. The malonamide-type PMOs are capable to adsorb large amounts of ibuprofen $(130 \mathrm{mg} / \mathrm{g})$ as a hydrophobic model drug. Release experiments are performed in a phosphate buffer solution at $\mathrm{pH} 7.4$ and show a controlled desorption of lbuprofen over 24 hours; a largely expanded times pan compared to mesoporous silicas. Moreover, we are able to tune the release profile by varying the content of organic bridges in the PMO pores.
\end{abstract}

Keywords:

\section{INTRODUCTION}

Since the discovery of Periodic Mesoporous Organosilicas (PMOs) in $1999^{1}$ as an evolution from M41S and SBA15 ordered silicas, these advanced hybrid materials have been the centre of profound research. ${ }^{2}$ Generally, PMOs are synthesized by the hydrolysis and subsequent condensation of a silsesquioxane precursor, typically ( $\left.\mathrm{R}^{\prime} \mathrm{O}\right)_{3} \mathrm{Si}-$ $\mathrm{R}-\mathrm{Si}(\mathrm{OR})_{3}$, around a micelle template. The organic $\mathrm{R}$ group allows the incorporation of a functional bridge into the siloxane framework of PMO materials. In this way, the advantages of mesoporous silicas (MPS), such as an ordered pore structure with a tunable pore size and a high internal surface area, are combined with a nonleachable built-in functionality. Furthermore, the organic bridge also allows introducing certain hydrophobicity into the framework. This greatly increases the hydrothermal and mechanical stability of PMOs, ${ }^{3}$ as the siloxane bridge

*Authors to whom correspondence should be addressed. is less susceptible to hydrolysis compared to pure silica materials.

In recent years a plethora of different functional bridges have been reported, delivering multi-purpose carriers for very diverse applications in for example catalysis, ${ }^{4}$ adsorption, ${ }^{5}$ chromatography, ${ }^{6}$ low- $k$ insulators ${ }^{7}$ and photoluminescence. ${ }^{8}$ Moreover, the chemical stability and non-toxic nature of PMO materials have lately led to a largely emerging field in biomedical applications such as supports for enzymatic bio-catalysis ${ }^{9}$ and protein enrichment and refolding. ${ }^{10}$

Controlled administration of drug molecules however remains a challenge, regarding such systems need to control the rate and period of drug delivery to maintain therapeutic drug levels during treatment, instead of a typical spike or burst release in classical therapy. Biodegradable polymers are often used as a host material for controlled drug release (CDR). ${ }^{11}$ The mechanical mixing of the drug with the polymer matrix is required to load the drug onto 
the polymer. However, this often leads to inhomogeneous distribution of the therapeutics, which in its turn gives mediocre results in terms of controlled release.

Porous materials (i.e., MPS, ${ }^{12}$ hydroxyapatite, ${ }^{13}$ metalorganic frameworks ${ }^{14}$ ) are shown to be very promising candidates as controlled drug delivery systems due to their large internal surface area and arranged pore systems, which allows a high and homogeneous uptake of both easily and poorly water-soluble therapeutic drugs. Numerous model drugs, such as ibuprofen, itraconazole, naproxen, aspirin, captopril, etc., have been screened in MPS. ${ }^{15}$ The biocompatibility of silica-based materials makes them especially attractive alternatives as for example regulated delivery of an anti-inflammatory drug (ibuprofen) can be combined with the possibility to bone tissue regeneration. ${ }^{13(b), 15}$ Furthermore, MPS have been shown to enhance oral bioavailability of poorly watersoluble drugs. ${ }^{16}$

Tailoring the pore size through the use of different surfactants influences the release profile of ibuprofen (IBU) from MCM-41 type silicas. ${ }^{17}$ However, a slower release rate is accompanied with a decrease of total IBU amount released as IBU molecules are physically entrapped inside the small pores. Research on SBA-15 type materials showed total release of all IBU adsorbed. ${ }^{18}$ The use of these large-pored materials as CDR system is however disputable as the total IBU dose is released within 2-3 h.

The Vallet-Regi research group observed delayed IBU-release from MCM-41 grafted with 3-aminopropyl(triethoxy)silane and attributed this to altered host-drug interactions on the surface of the silica matrix. ${ }^{19}$ Poor hydrolytic stability of the grafted Si-O-Si bond renders such an approach inapplicable in the human body as undesired leaching of the functionality might occur. Research on ethyl-bridged PMOs illustrated the effects of hydrophobicity on the release profile of a very hydrophobic drug such as tetracycline. ${ }^{20}$ Also, CDR was demonstrated on carboxylic acid functionalized PMOs. ${ }^{21}$ In both cases, however, a significant drop in total amount of drug released is observed as drug molecules are too strongly adsorbed to the carrier.

Recently, Moorthy et al., created amphoteric bis-silane precursors to obtain stimuli-responsive $(\mathrm{pH})$ functionalities inside the pore walls of a PMO. ${ }^{22}$ Amphoteric urylene and amidoxime moieties were suggested to influence the release behavior of loaded drug molecules via weak and reversible interactions such as electrostatic, hydrophobic-hydrophobic and H-bonding interactions, while only slightly affecting the amount of drugs released. Also, this $\mathrm{pH}$ dependent interaction implies that no intricate pore-capping molecules or 'gatekeepers' must be employed to avoid premature drug release.

Amide-resonance is very interesting for CDR as this effect provides both amphoteric as well as normal amide character. Hence, all of the latter interactions might occur in a reversible way. This may drastically influence the release profile of IBU, as a model drug, and ensures a high release of all adsorbed drug molecules. Therefore, this contribution proposes to synthesize new tailor-made bis(3-(triethoxysilyl)propyl)malonamide (MA) and $N, N$-dimethyl$N, N$-bis(3-(triethoxysilyl)propyl)malonamide (mMA) precursors which are subsequently condensed around a large co-block polymer template (P123) to form PMO materials with large pores to avoid irreversible entrapment of IBU. Both MA and mMA functionalities are possible drug interaction sites. The nature of the occurring interaction is assessed through a comparison of both materials as for the methylated, tertiary amide functionality of an mMA-PMO the $\mathrm{N}-\mathrm{H}$ group, capable of $\mathrm{H}$-bonding, is exchanged for a N-Me group with increased hydrophobicity. The (m)MA PMO materials are evaluated as CDR-matrices for IBU in a phosphate buffer solution (PBS) at $\mathrm{pH} 7.4$ and body temperature. To investigate the tunability of the release profile, PMOs with a varying functional loading are synthesized.

\section{EXPERIMENTAL SECTION}

\subsection{Materials}

(3-aminopropyl)triethoxysilane (APTES, 98\%) and (Nmethyl-3-aminopropyl)trimethoxysilane (mAPTMS) were purchased from ABCR/Gelest. Malonylchloride (97\%), tetraethylorthosilicate (TEOS, 98\%), Pluronic P123 $\left(\mathrm{EO}_{20} \mathrm{PO}_{70} \mathrm{EO}_{20}, \mathrm{M}_{n}=5800\right)$ and triethylamine (>99\%) were obtained form Sigma-Aldrich. Ibuprofen was acquired from TCI Europe and anhydrous diethylether (Rotidry, >99.5\%), $\mathrm{HCl}(37 \%)$ and hexane (>95\%) from Carl Roth. All reagents and solvents were used as received without further purification.

\subsection{Synthesis of Novel Malonamide-Type Precursors}

To a solution of APTES (16.11 ml; $68 \mathrm{mmol})$ and triethylamine $(9.60 \mathrm{ml} ; 68 \mathrm{mmol})$ in $150 \mathrm{ml}$ of dry diethylether under inert atmosphere at $0{ }^{\circ} \mathrm{C}$, a solution of malonylchloride (5 g; $34 \mathrm{mmol})$ in $100 \mathrm{ml}$ dry diethylether was added dropwise over 30 min while heavily stirring. This water-free Schotten-Baumann reaction (Fig. 1) was selected to avoid hydrolysis of the silsesquioxane species in the reaction. After $15 \mathrm{~min}$, stirring was switched off and the reaction mixture was left to stand overnight. After filtration of a white precipitate, diethyl ether was evaporated under reduced pressure resulting in bis(3-(triethoxysilyl)propyl)malonamide (1) as a red viscous oil. $N, N$-dimethyl- $N, N$-bis(3(trimethoxysilyl)propyl)malonamide (2) is obtained as a slightly viscous orange oil via an analogous reaction of mAPTMS (14.02 ml; $68 \mathrm{mmol})$ and malonylchloride (5 g; $34 \mathrm{mmol})$.

1: ${ }^{1} \mathrm{H}$ NMR $\left(\mathrm{CDCl}_{3}\right): \delta=0.67\left(t, 4 \mathrm{H}, \mathrm{SiCH}_{2}\right)$, $1.21\left(t, 18 \mathrm{H}, \mathrm{OCH}_{2} \mathrm{CH}_{3}\right), 1.70$ (quint, $4 \mathrm{H}, \mathrm{SiCH}_{2} \mathrm{CH}_{2}$ ), $3.12\left(s, 2 \mathrm{H}, \mathrm{OCCH}_{2} \mathrm{CO}\right), 3.25\left(t, 4 \mathrm{H}, \mathrm{NHCH}_{2}\right), 3.83$ 


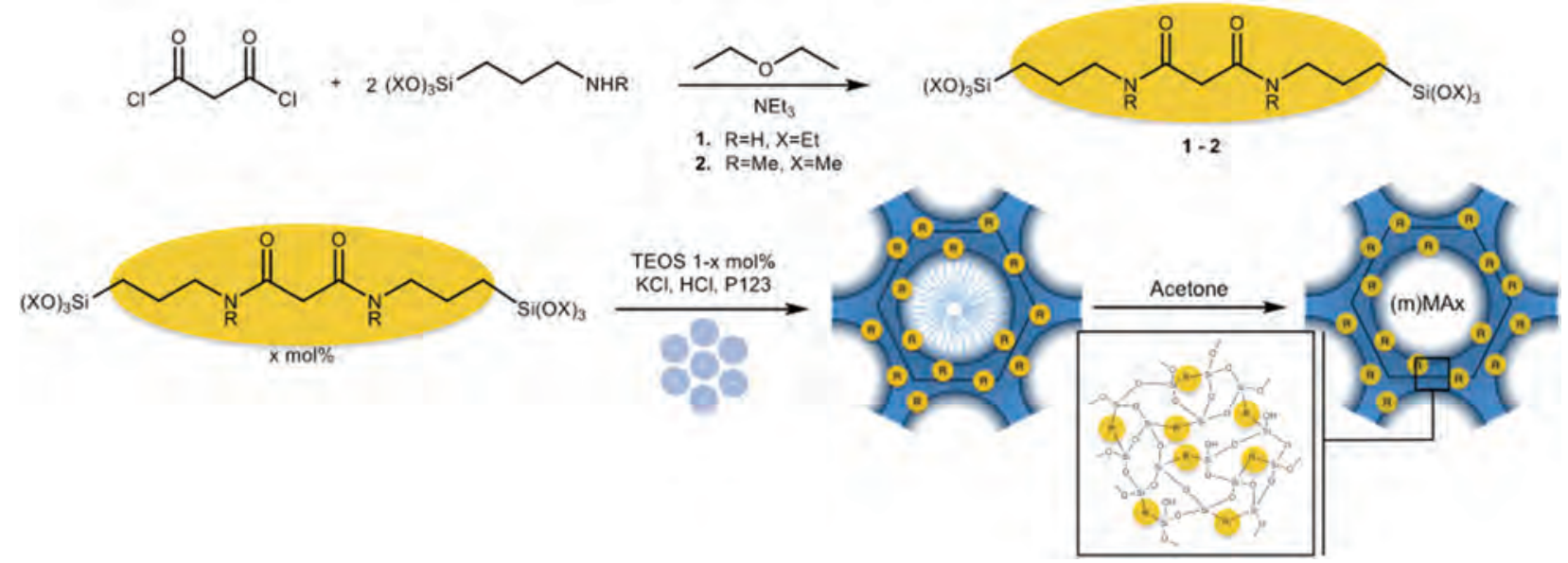

Fig. 1. Synthesis of bis(3-(triethoxysilyl)propyl)malonamide (1), $N, N$-dimethyl- $N, N$-bis(3-(trimethoxysilyl)propyl)malonamide (2) and the respective PMOs. MA and mMA PMOs are synthesized with $\times$ mol\% of $\mathbf{1}$ and $\mathbf{2}$ respectively.

$\left(q, 12 \mathrm{H}, \mathrm{OCH}_{2}\right) ;{ }^{13} \mathrm{C} \mathrm{NMR}\left(\mathrm{CDCl}_{3}\right): \delta=9.8\left(\mathrm{SiCH}_{2}\right)$, $19.3\left(\mathrm{OCH}_{2} \mathrm{CH}_{3}\right), 22.8\left(\mathrm{SiCH}_{2} \mathrm{CH}_{2}\right), 42.1\left(\mathrm{NHCH}_{2}\right), 42.5$ $\left(\mathrm{OCCH}_{2} \mathrm{CO}\right), 58.7\left(\mathrm{OCH}_{2}\right), 166(\mathrm{C}=\mathrm{O})$.

2: ${ }^{1} \mathrm{H}$ NMR $\left(\mathrm{CDCl}_{3}\right): \delta=0.63\left(t, 4 \mathrm{H}, \mathrm{SiCH}_{2}\right), 1.65$ (quint, $\left.4 \mathrm{H}, \mathrm{SiCH}_{2} \mathrm{CH}_{2}\right), 2.91\left(s, 6 \mathrm{H}, \mathrm{NCH}_{3}\right), 3.02(t, 4 \mathrm{H}$, $\left.\mathrm{NCH}_{2}\right), 3.50\left(s, 2 \mathrm{H}, \mathrm{OCCH}_{2} \mathrm{CO}\right), 3.60\left(s, 18 \mathrm{H}, \mathrm{OCH}_{3}\right)^{13} \mathrm{C}$ $\operatorname{NMR}\left(\mathrm{CDCl}_{3}\right): \delta=9.7\left(\mathrm{SiCH}_{2}\right), 21.4\left(\mathrm{SiCH}_{2} \mathrm{CH}_{2}\right), 35.8$ $\left(\mathrm{NCH}_{3}\right), 50.2\left(\mathrm{OCH}_{3}\right), 50.3\left(\mathrm{OCCH}_{2} \mathrm{CO}\right), 52.6\left(\mathrm{NCH}_{2}\right)$, $167(\mathrm{C}=\mathrm{O})$.

\subsection{Preparation of MA- and mMA-PMOs}

Malonamide (MA) and N-methyl malonamide (mMA) PMOs were synthesized in a typical hydrothermal procedure with a following molar ratio, $\mathrm{P} 123: \mathrm{H}_{2} \mathrm{O}: \mathrm{HCl}: \mathrm{KCl}$ : 1(2):TEOS-0.172:1876:60.9:49.3:x:10-x. P123, as a structure directing agent was dissolved in the aqueous solution of $\mathrm{HCl}$ and $\mathrm{KCl}$. To this solution, a mixture with varying amounts of PMO-precursor and TEOS was added. Stirring was continued for $24 \mathrm{~h}$ at $40{ }^{\circ} \mathrm{C}$, followed by an ageing step of $24 \mathrm{~h}$ at $95{ }^{\circ} \mathrm{C}$. In the course of the stirring step an orange solid was formed, which was eventually filtered off and thoroughly washed with $3 \times 20 \mathrm{ml} \mathrm{H}_{2} \mathrm{O}$ en $3 \times 20 \mathrm{ml}$ acetone. The P123 template was removed via a Soxhlet extraction in acetone for $5 \mathrm{~h}$, after which the products were vacuum dried at $120{ }^{\circ} \mathrm{C}$. All samples were named based on the precursor (MA, mMA) and its initial molar percentage $(x)$ relative to the total amount of Si-sources.

\subsection{Drug Loading Procedure and In-Vitro CDR Experiments}

In a procedure adapted from Song et al., ${ }^{18}$ a stock solution of $1 \mathrm{~g} / \mathrm{L}$ IBU in hexane was prepared to perform adsorption experiments. Routinely, $50 \mathrm{mg}$ of (m)MAx-PMO was added to $50 \mathrm{ml}$ of the IBU/hexane solution in a closed vessel. This was shaken for $24 \mathrm{~h}$ in a temperature controlled environment at $25^{\circ} \mathrm{C}$, suspending all PMO particles. The
IBU-loaded materials were filtered off, swiftly washed with $10 \mathrm{ml}$ hexane and vacuum dried at room temperature. A UV-VIS spectrometer (Shimadzu UV-1800 Spectrophotometer, $272 \mathrm{~nm}$ ) was used to determine the amount of IBU loaded on the solids, by change of the IBU concentration in the hexane solution before and after the adsorption experiment. All experiments were at least performed in threefold.

CDR experiments were conducted in-vitro in a PBS $\left(\mathrm{pH} 7.4,37{ }^{\circ} \mathrm{C}\right)$ to mimic conditions of human fluids. Approximately $30 \mathrm{mg}$ of IBU-(m)MAx samples were inserted in a membrane dialysis bag $\left(\mathrm{M}_{w}\right.$ cut-off: $12.4 \mathrm{kDa}$ ) where upon they were suspended in $250 \mathrm{ml}$ of PBS. Gentle stirring was applied to reduce external diffusion effects. A release profile was determined through UV-VIS spectroscopy of $3 \mathrm{ml}$ aliquots at set times.

\subsection{Characterisation}

NMR spectra $\left({ }^{1} \mathrm{H},{ }^{13} \mathrm{C}\right)$ of precursor 1 and 2, dissolved in $\mathrm{CDCl}_{3}$, were recorded on a Bruker $300 \mathrm{MHz}$ AVANCE spectrometer. Chemical shifts $(\delta)$ are expressed in ppm relative to a tetramethylsilane standard. X-Ray Powder Diffraction (XRPD) pattern of the PMO materials were recorded on a Thermo Scientific ARL X'TRA X-ray diffractometer using $\mathrm{Cu} \mathrm{K} \alpha$ radiation of $40 \mathrm{kV}$ and $30 \mathrm{~mA}$. A Micromeretics Tristar 3000 was used for $\mathrm{N}_{2}$-sorption experiments at $77 \mathrm{~K}$ to obtain the internal surface area $\left(\mathrm{S}_{\mathrm{BET}}\right)$ and pore size distribution $\left(\mathrm{PS}_{\mathrm{BJH}}\right)$ making use of the $\mathrm{BET}$ and $\mathrm{BJH}$ theory respectively. Prior to measurement, all samples were vacuum dried at $120{ }^{\circ} \mathrm{C}$ to evacuate all adsorbed water. Diffuse Reflectance Infrared Spectroscopy (DRIFTS) was performed using a Thermo Nicolett 6700 FT-IR spectrometer equipped with a Greasby-Specac diffuse reflectance cell, modified to measure samples at $120{ }^{\circ} \mathrm{C}$ under vacuum. For CHNS analysis, a Thermo Flash 2000 elemental analyser was used with $\mathrm{V}_{2} \mathrm{O}_{5}$ as catalyst. Thermogravitational Analysis (TGA) was performed 
on a Netzsch STA 449 F3 Jupiter with a heating rate of $10{ }^{\circ} \mathrm{C} / \mathrm{min}$ and an air flow of $120 \mathrm{ml} / \mathrm{min}$. Transmission electron microscopy (TEM) images were taken on a JEOL JEM 2200-FS TEM. The ${ }^{13} \mathrm{C}$ CP/MAS NMR and ${ }^{29} \mathrm{Si}$ MAS NMR spectra were recorded at 100.61 and 79.49 MHz, respectively, on a Bruker AVANCE-400 WB dual channel spectrometer at room temperature with chemical shifts relative to a tetramethylsilane standard. An overall 1000 free induction decays were accumulated. The excitation pulse and recycle time for ${ }^{13} \mathrm{C}$ CP/MAS NMR spectra were $6 \mu \mathrm{s}$ and $2 \mathrm{~s}$, respectively, and those for ${ }^{29} \mathrm{Si}$ MAS NMR spectra $6 \mu \mathrm{s}$ and $60 \mathrm{~s}$.

\section{RESULTS AND DISCUSSION}

\subsection{Structural Assessment}

X-ray diffractograms (Fig. 2) show clear long-range structural ordering at low diffraction angles $(2 \theta)$ of the m(MA)PMO materials as expected for template-based ordered mesoporous materials with amorphous pore walls. An intense (100) peak combined with the presence of two minor second-order (110) and (200) peaks, are indicative for a 2D-hexagonal (P6 $\mathrm{mm})$ pore structure of the materials. Increasing the loading of the functional organic bridge, a decrease in structural ordering is observed, together with a shift of $d$-spacing to lower values, pointing to a decrease of the unit cell parameter $a_{0}$ (Table I). Ultimately, all ordering is lost for MA-PMO materials with

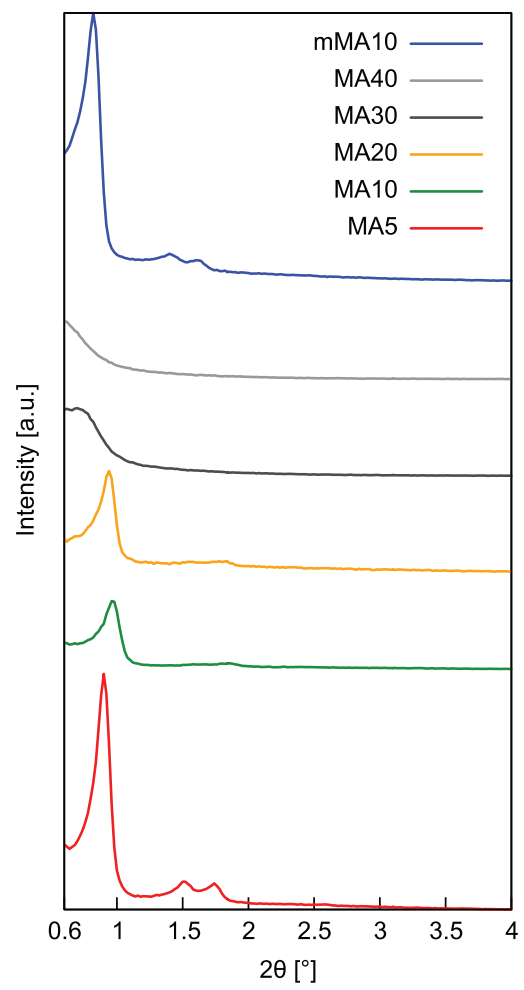

Fig. 2. X-ray diffraction patterns of MA5 (bottom), MA10, MA20, MA30, MA40 and mMA10 (top). more than 20 mol\% of MA-precursor. This amount of precursor molecules, with relatively long and flexible organic bridges, can no longer be properly arranged around the micellating template. ${ }^{2(c)}$ Compared to its MA counterpart, a profound amelioration of the ordering is seen from the XRD patterns of mMA10, which is most likely originating from a better template-precursor interaction due to the extra hydrophobicity of the methyl groups.

Similar trends are observed through nitrogen adsorption-desorption experiments (Fig. 3). MA5, 10, 20 and mMA10 all show type-IV isotherms with $\mathrm{H} 1$ hysteresis, typical for SBA15-like materials prepared with P123 as a template. The high specific surface area $\left(\mathrm{S}_{\mathrm{BET}}\right)$ of MA5 and mMA10 drops significantly from 545 and $621 \mathrm{~m}^{2} / \mathrm{g}$ respectively, to $276 \mathrm{~m}^{2} / \mathrm{g}$ for MA20 (Table I). Also the pore volume $\left(V_{\mathrm{p}}\right)$ and pore diameter $\left(d_{\mathrm{BJH}}\right)$ are affected in the same way, ranging from $\sim 0.9 \mathrm{~mL} / \mathrm{g}$ and $6.8 \mathrm{~nm}$ for MA5 and mMA10 to $0.41 \mathrm{~mL} / \mathrm{g}$ and $5.0 \mathrm{~nm}$ for MA20, all with narrow pore size distribution (Fig. 4). In agreement with XRD results, $\mathrm{N}_{2}$-isotherms of MA30 and MA40 suggest weak porosity due to the lack of ordering, resulting in a low specific surface area and an unreliable pore size distribution.

TEM-images (Fig. 5) show a clear visual confirmation of the $2 \mathrm{D}$ ordered conformation of the PMO pores. Based on these images, the estimated pore size is $7.0 \mathrm{~nm}$ and $5.0 \mathrm{~nm}$ for MA5 and MA20 respectively with $\mathrm{a}_{0} \sim 9 \mathrm{~nm}$ and $8.4 \mathrm{~nm}$, which is in great accordance with XRD and $\mathrm{N}_{2}$-sorption results. Very striking in the images are the thicker pore walls, obtained as a result of a higher organic content. Combined with the increased hydrophobicity, this effect generally contributes to the increased hydrothermal stability of PMOs compared to non-functional silicas. ${ }^{3(a), 23}$

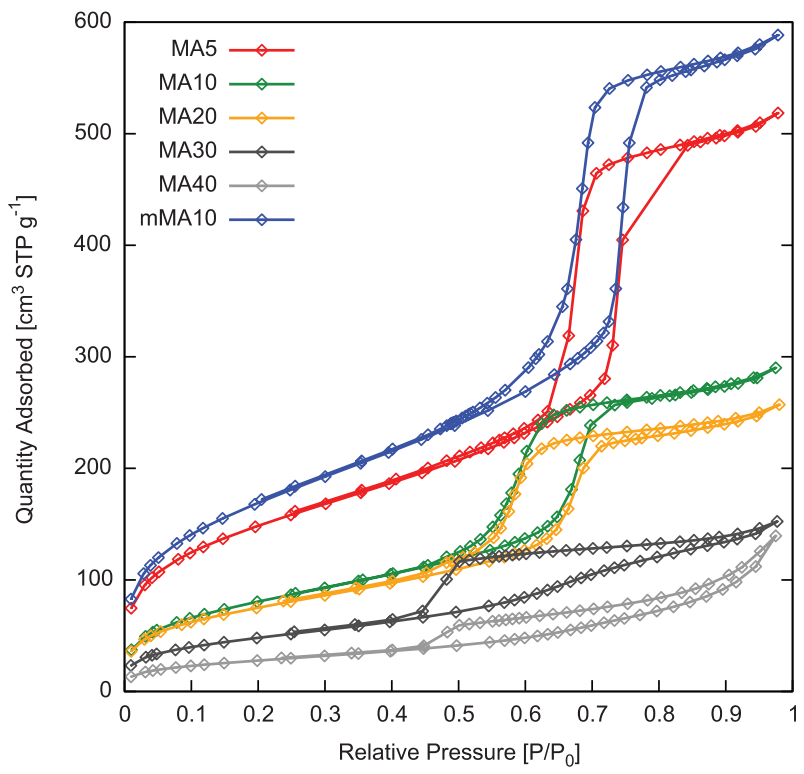

Fig. 3. $\mathrm{N}_{2}$ adsorption-desorption isotherms of MA40 (bottom), MA30, MA20, MA10, MA5 and mMA10 (top).

Adv. Porous Mater. 2, 1-8, 2014 


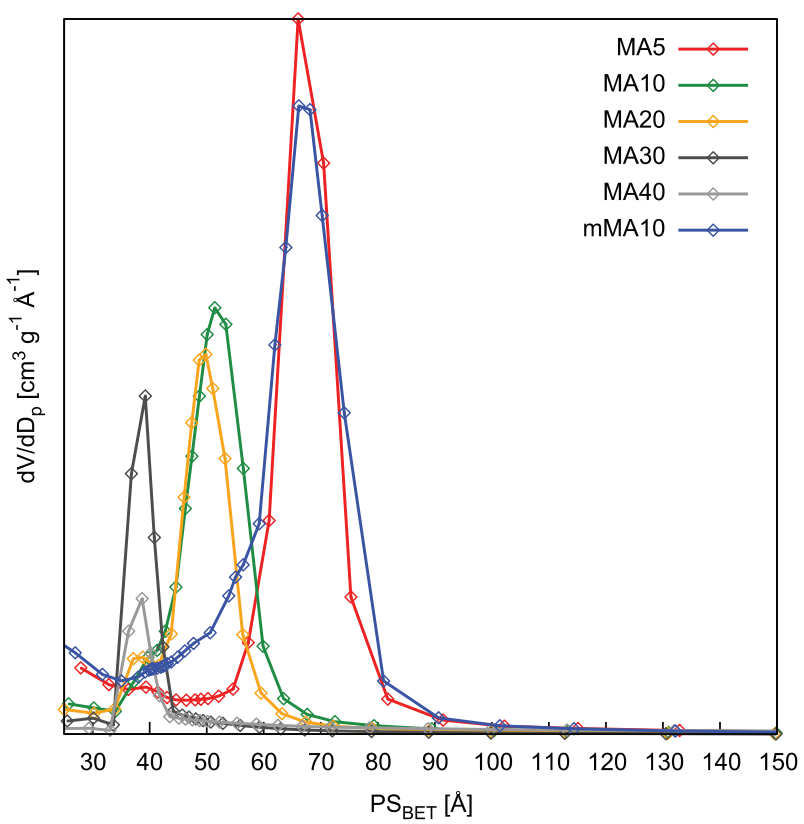

Fig. 4. Pore size distribution (BJH) of MA5 and mMA10 $(\sim 7 \mathrm{~nm})$, MA10 and MA20 ( $5 \mathrm{~nm})$ and MA30 and MA40.

\subsection{Analysis of Functionalities Inside the Pore Walls}

The DRIFT spectra of all samples (Fig. 6) show characteristic C-H stretch vibrations at 2970, 2940 and $2890 \mathrm{~cm}^{-1}$, originating from the propyl-group in the organic bridge. For MA-PMOs, peaks at $1650 \mathrm{~cm}^{-1}$ and $1540 \mathrm{~cm}^{-1}$ are assigned to Amide I ( $\mathrm{C}=\mathrm{O}$ stretch) and Amide II $(\mathrm{N}-\mathrm{H}$ bend) vibrations, thus indicating the presence of a secondary amide in the PMO material. An increased relative intensity of these peaks is observed for samples with a higher mol\% of the MA-precursor. Expected N-H stretch vibrations possibly contribute to the broadened band from residual adsorbed $\mathrm{H}_{2} \mathrm{O}$ at $3300 \mathrm{~cm}^{-1}$. As mMA10 carries tertiary amide functionalities in its pore walls, the $\mathrm{N}-\mathrm{H}$ bending vibration is absent. The $\mathrm{C}=\mathrm{O}$ stretch peak remains present but is slightly red shifted to $1620 \mathrm{~cm}^{-1}$. Almost complete removal of the P123 template by acetone extraction is assumed as no significant $\mathrm{C}-\mathrm{H}$ bending vibrations are observed around $1350 \mathrm{~cm}^{-1}$. All samples show a broad adsorption band between 1250-1000 $\mathrm{cm}^{-1}$ that indicates the formation of the framework's siloxane $(\mathrm{Si}-\mathrm{O}-\mathrm{Si})$ bonds. Deformation of this band may be attribute to more forced binding angles of the lengthy silsesquioxane moieties to form the curved pores wall. Residual silanol ( $\mathrm{Si}-\mathrm{OH})$ peaks show up at $950 \mathrm{~cm}^{-1}$, indicating that the condensation of the precursors is not complete.

The latter is also observed in the ${ }^{29} \mathrm{Si}$ MAS NMR spectrum of MA20 in which both $\mathrm{Q}^{n}\left(\mathrm{Q}^{n}=\mathrm{Si}(\mathrm{OSi})_{n}(\mathrm{OH})_{4-n}\right)$ and $\mathrm{T}^{n}\left(\mathrm{~T}^{n}=\mathrm{RSi}(\mathrm{OSi})_{n}(\mathrm{OH})_{3-n}\right)$ signals are seen (Fig. 7). The prominent $\mathrm{Q}^{4}$ peak at $-110 \mathrm{ppm}$ is only accompanied by a $\mathrm{Q}^{3}$ shoulder at $-100 \mathrm{ppm}$, thus indicating a high degree of condensation of the siloxane network. A $\mathrm{Q}^{2}$

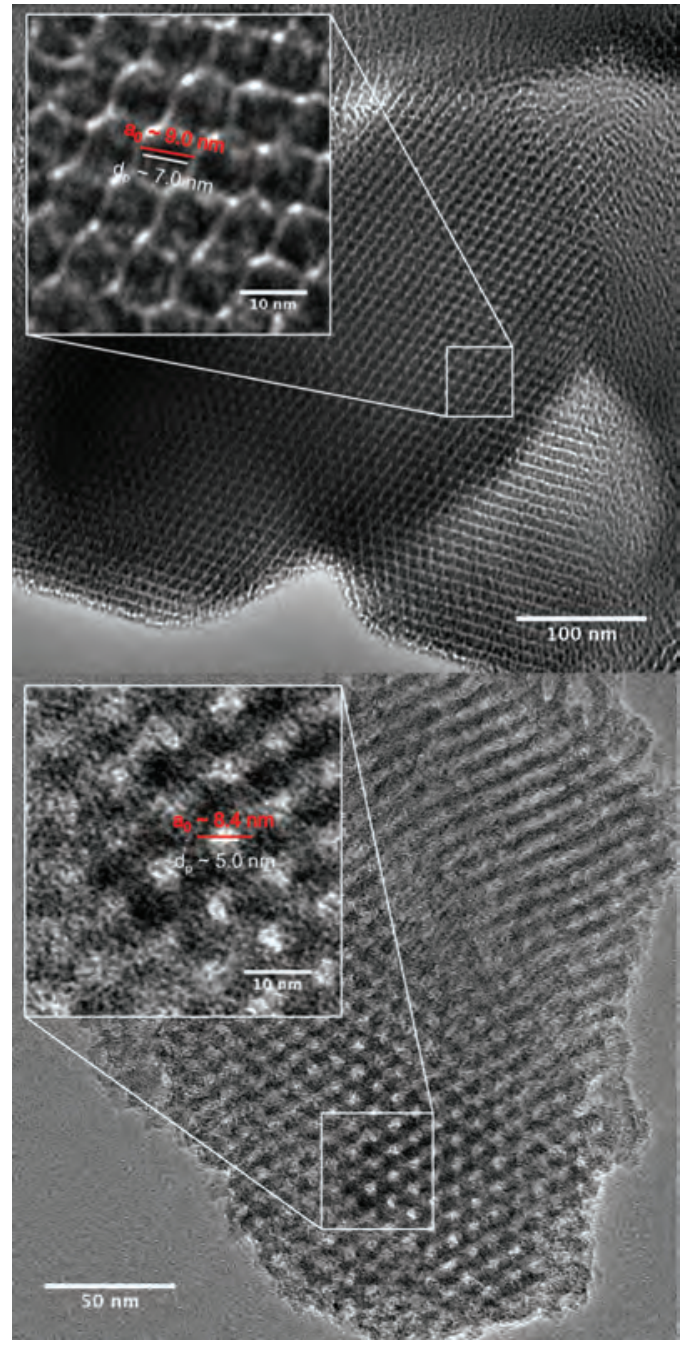

Fig. 5. TEM images of representative materials, MA5 (top) and MA20 (bottom). Inset: Zoom of pore size $\left(d_{\mathrm{p}}\right)$ and unit cell parameter $\left(a_{0}\right)$.

signal of geminal silanols is completely absent. The presence of $\mathrm{T}^{3}$ and $\mathrm{T}^{2}$ signals ( -63 and $\left.-52 \mathrm{ppm}\right)$ confirms the total incorporation of silsesquioxane into the pore wall, again with the occurrence of a high condensation degree and without cleavage of the $\mathrm{Si}-\mathrm{C}$ bond under synthetic conditions.

Figure 8 displays the ${ }^{13} \mathrm{C}$ MAS NMR spectrum of MA20. Signals at 9.6, 22.1 and $42.9 \mathrm{ppm}$ arise from the propylic moiety of the built in MA-functionality, being the carbon shift of $\mathrm{Si}-\mathrm{CH}_{2}, \mathrm{Si}-\mathrm{CH}_{2}-\mathrm{CH}_{2}$ and $\mathrm{CH}_{2}-\mathrm{NH}$ respectively. This last signal majorly overlaps the signal of the methylene group in between the carbonyl groups, which may be seen as a faint shoulder at $45.2 \mathrm{ppm}$. The amide carbonyl signal is situated at $168 \mathrm{ppm}$. This result confirms the unaltered fixation of MA functionalities in the PMO structures.

The exact amount of (m)MA functionalities in the PMO framework was quantitatively determined by elemental analysis (CHNS) (Table I). Via the nitrogen content a 


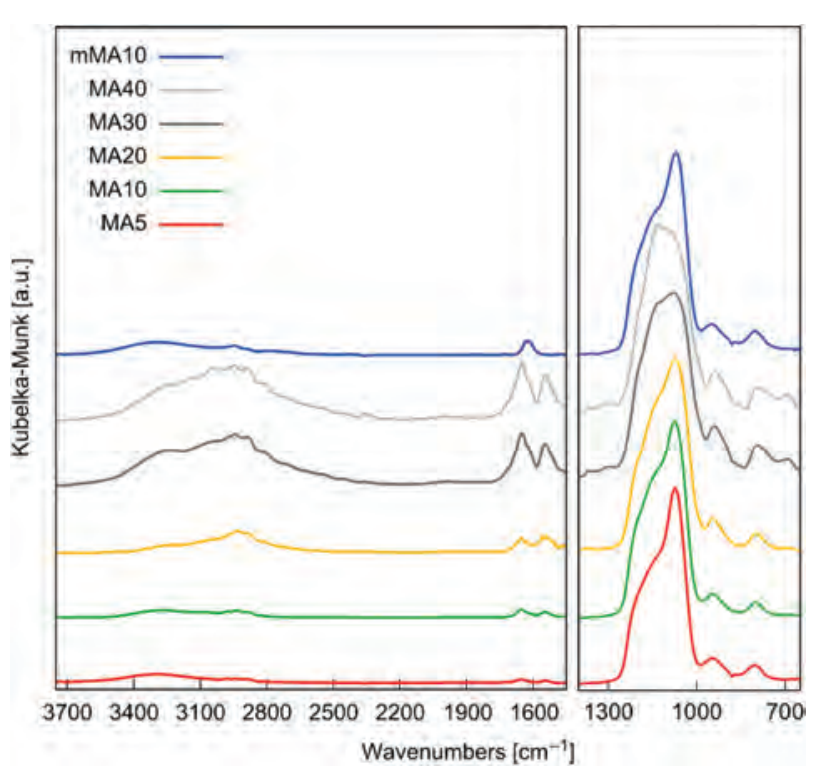

Fig. 6. DRIFT spectra of MA5 (bottom), MA10, MA20, MA30, MA40 and mMA10 (top). Intensity of the signal in the $3750 \mathrm{~cm}^{-1}-1450 \mathrm{~cm}^{-1}$ interval is enhanced for clarity.

maximum loading of $2.28 \mathrm{mmol} / \mathrm{g}$ was found for MA40. At lower loading, MA5 and MA10, the entire amount of used precursor was incorporated in the final materials. However, for higher mole fractions a decrease of framework functionality is found compared to the initial mixture. This might be a result of the increased difficulty to arrange a higher amount of long bis-silane molecules around the template. Additional TGA experiments are consistent with elemental analysis, as a greater weight loss is observed with increasing functional loading (Fig. 9). Moreover, TGA analysis shows that the investigated PMOs are thermally stable up to approximately $270{ }^{\circ} \mathrm{C}$, after which deterioration of the organic bridges occurs.

\subsection{Ibuprofen Adsorption and CDR}

Ever since the discovery of CDR systems, development of new materials with different properties is ongoing.

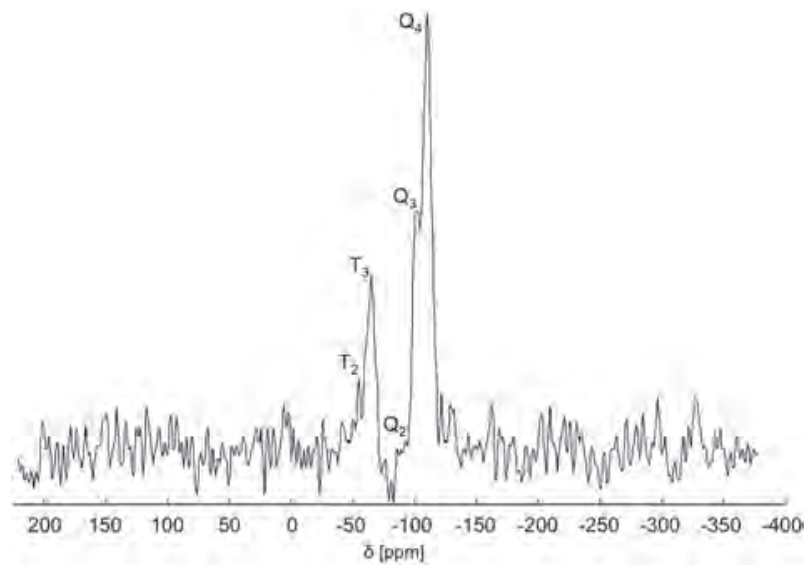

Fig. 7. ${ }^{29}$ Si MAS NMR spectrum of MA20 as a representative material.

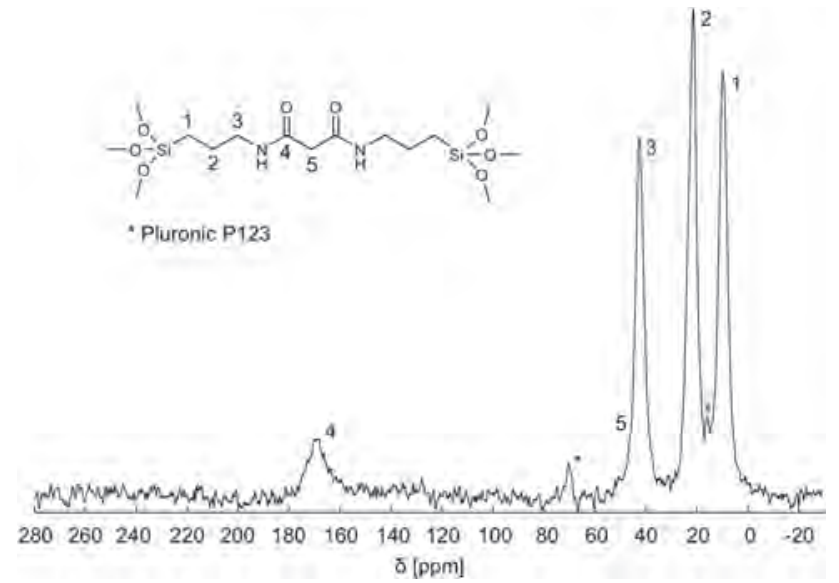

Fig. 8. ${ }^{13}$ C MAS NMR spectrum of MA20.

Such CDR systems should be able to deliver a fixed concentration of a therapeutic agent over a considerable times pan, preferably only in the targeted tissue, without exceeding a toxicity threshold as encountered for burst drug release. This concept can elegantly be tackled with all types of porous materials, ranging from nanoporous clays to polymer hydrogels, all allowing a vast intake of drug molecules due to surface-adsorption. Next to research on carriers for poorly water-soluble drugs, a main focus is the optimization of the drug release profile by means of the physical characteristics of the materials involved, such as porosity and particle size. More recently, PMOs were proposed as promising CDR systems as a result of their large internal surface, chemical stability, biocompatibility, non-toxicity and easy adaptation of the structural parameters. The main advantage of these organic-inorganic hybrid drug carriers is the possibility to incorporate organic functionalities, which interact with the drug molecule via non-covalent interactions. The nature of these functionalities greatly influences the

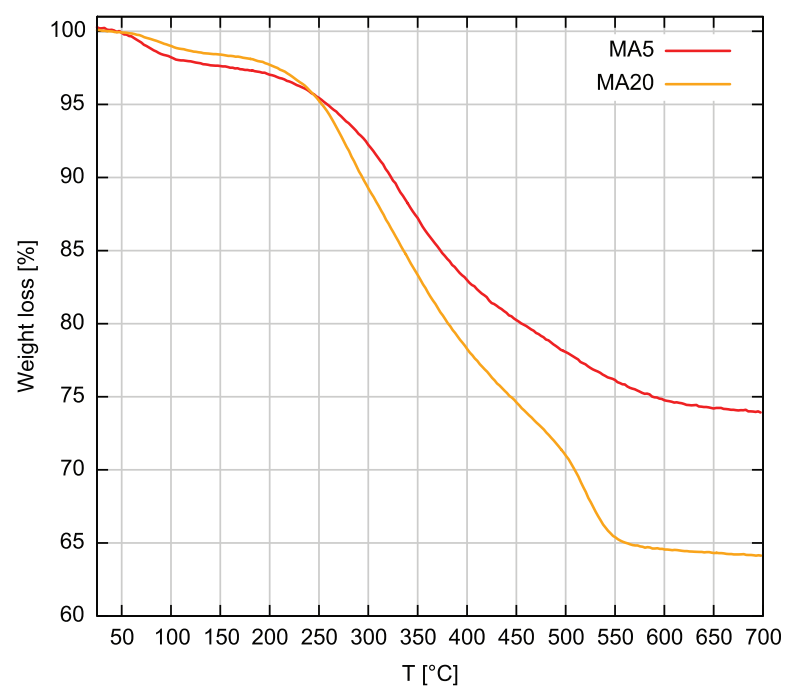

Fig. 9. TGA profile of MA20 (bottom) and MA5 (top).

Adv. Porous Mater. 2, 1-8, 2014 
adsorption and subsequent release of drugs as different drug-matrix interactions may emerge. In this study, secondary and tertiary amides are proposed as functional PMO-bridge to influence the adsorption and release rate of ibuprofen. This hydrophobic anti-inflammatory drug is used as a model drug as it has a small estimated dynamic radius of $1 \mathrm{~nm}$, thus avoiding physical pore size limitations, which are suggested to initiate a delayed release for MCM-type materials. ${ }^{12}$

Adsorption experiments (Table II) were only performed on a selection of samples, which show good pore ordering. A high uptake of IBU, up to $0.303 \mathrm{mg} / \mathrm{m}^{2}$ for MA20, was found via UV-VIS measurements of a hexane solution before and after drug adsorption. With higher functional loading, intrinsically more IBU is loaded in the PMO pores, taking into account the varying internal surface of the PMOs. This confirms the occurrence of increased interactions, most likely H-bonding and hydrophobichydrophobic interactions, between IBU and the PMOmatrix. No noticeable variation in adsorption is observed for the mMA-PMO with an extra methyl group. XRD of IBU loaded samples show no peaks from crystalline IBU, thus proving that IBU is adsorbed all over the pore walls as an amorphous phase. This is verified by $\mathrm{N}_{2}$-sorption. After adsorption, the surface area $\left(\mathrm{S}_{\mathrm{BET}}\right)$ drops from $545 \mathrm{~m}^{2} / \mathrm{g}$ to $311 \mathrm{~m}^{2} / \mathrm{g}$ and from $276 \mathrm{~m}^{2} / \mathrm{g}$ to $168 \mathrm{~m}^{2} / \mathrm{g}$ for MA5 and MA20 respectively. Combined with a decrease of pore size diameter $\left(d_{\mathrm{BJH}}\right)$ from $6.8 \mathrm{~nm}$ to $6.0 \mathrm{~nm}$ and $5.0 \mathrm{~nm}$ to $4.3 \mathrm{~nm}$, this indicates that IBU has partly filled the mesopores.

CDR profiles of MA5 and M20 are depicted in Figure 10. After a minor initial burst release of IBU adsorbed on the external surface of the PMO particles, clear controlled release behaviour is shown for both

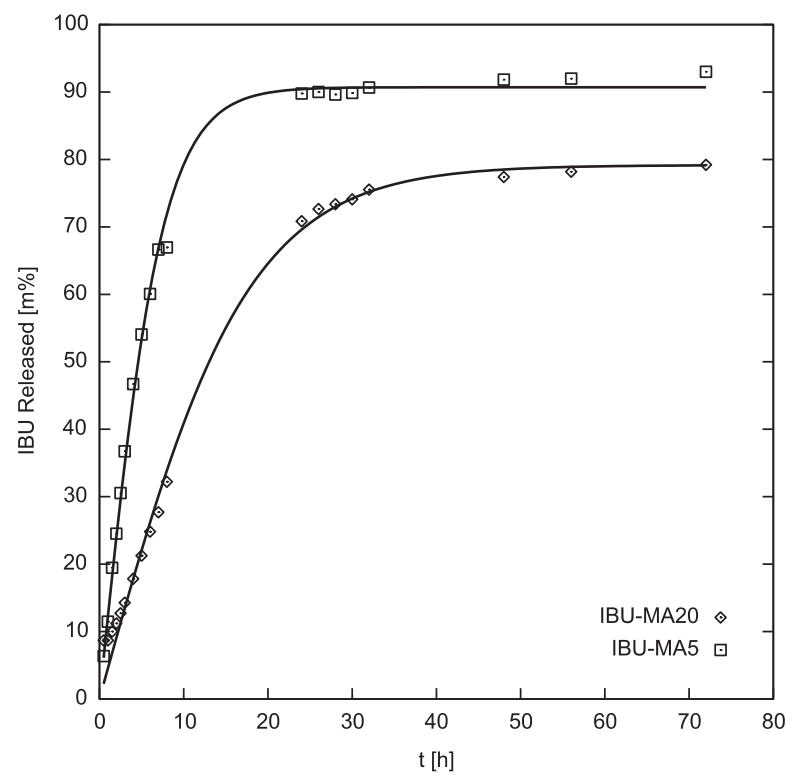

Fig. 10. IBU release profile of MA5 (top) and MA20 (bottom).

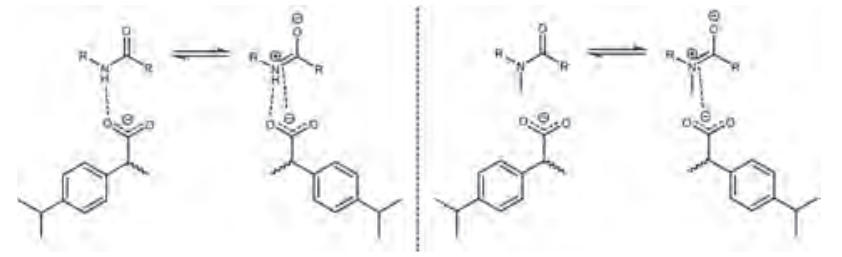

Fig. 11. Representation of electrostatic and H-bonding interactions of IBU with a MAx (left) and mMAx (right) PMOs.

materials. Drug delivery as a function of time remains linear for approximately $8 \mathrm{~h}\left(0.083 \mathrm{~m} \% \mathrm{IBU}_{\text {rel }} / \mathrm{h}\right)$ for MA5, which is a major improvement compared to SBA-15. ${ }^{18}$ A maximum of $93 \mathrm{~m} \%$ IBU is released after $72 \mathrm{~h}$ in the PBS at pH 7.4. Release of IBU loaded onto MA20 is clearly slower with a linear profile up to $24 \mathrm{~h}(0.026 \mathrm{~m} \%$ $\left.\mathrm{IBU}_{\text {rel }} / \mathrm{h}\right)$ as a result of the increased functional loading. Due to this slow release rate, less $(79 \mathrm{~m} \%)$ of the adsorbed IBU is released after $72 \mathrm{~h}$. All this may be ascribed to the fact that a higher MA-loading ensures more interactions between IBU and the pore walls. Most likely, a major contribution to these interactions is the electrostatic attraction between the negatively charged IBU at pH 7.4 and the charged, amphoteric resonance structures of the amide functionalities in the pore walls. Controlling the functional amide loading during synthesis, gives PMO materials with specific and tunable CDR properties. However, release experiments with IBU-loaded mMA10 $\left(0.01 \mathrm{~m} \% \mathrm{IBU}_{\text {rel }} / \mathrm{h}\right)$ show no slower release rate because of the added hydrophobicity of the tertiary amide. On the contrary, a similar release profile as MA5 is found. Recent calculations on the resonance structures of acetamide show approximately $50 \%$ of amphoteric character for this molecule. ${ }^{24}$ Here, this character induces electrostatic interactions of IBU with both the MA as the mMA functionality. For the MA-PMOs, however, N-H groups of the secondary amide possibly remain available for extra H-bonding interactions especially within the other, noncharged amide resonance structure (Fig. 11). This effect is absent in the tertiary amide of mMA10 (N-Me group), resulting in a relatively faster IBU-release compared to MA5. This pronounced difference between the two materials might indicate $\mathrm{H}$-bonding interactions, which are only present for MAx-PMOs, also play a crucial role in the fine-tuning of the IBU-retention in the PMO pores.

\section{CONCLUSION}

Two novel malonamide and $\mathrm{N}$-methyl malonamide type PMOs have been successfully synthesized via the cocondensation of their respective precursors with TEOS in a hydrothermal process. Structural integrity was maintained up to a high functional loading of $1.34 \mathrm{mmol} / \mathrm{g}$ within the pore walls. This allows adsorbing high quantities of ibuprofen as a hydrophobic model drug inside the mesopores. The (m)MA PMOs are demonstrated to be efficient 
CDR systems for IBU in PBS ( $\mathrm{pH} 7.4$ ) with a controlled linear release rate of up to $24 \mathrm{~h}$ as a result of reversible host-drug interactions. Moreover, depending on the functional loading, one is able to tune the release properties for optimal IBU dosage.

Acknowledgment: The authors would like to thank Tom Planckaert for CHNS elemental analysis, Katrien Haustraete for Tem imaging and Ghent University for financial support.

\section{References and Notes}

1. (a) S. Inagaki, S. Guan, Y. Fukushima, T. Ohsuna, and O. Terasaki, J. Am. Chem. Soc. 121, 9611 (1999); (b) B. J. Melde, B. T. Holland, C. F. Blanford, and A. Stein, Chem. Mater. 11, 3302 (1999); (c) T. Asefa, M. J. MacLachlan, N. Coombs, and G. A. Ozin, Nature 402, 867 (1999).

2. (a) F. Hoffmann, M. Cornelius, J. Morell, and M. Froeba, Angewandte Chemie-International Edition 45, 3216 (2006); (b) N. Mizoshita, T. Tani, and S. Inagaki, Chem. Soc. Rev. 40, 789 (2011); (c) P. Van der Voort, D. Esquivel, E. De Canck, F. Goethals, I. Van Driessche, and F. J. Romero-Salguero, Chem. Soc. Rev. 42, 3913 (2013).

3. (a) W. P. Guo, X. Li, and X. S. Zhao, Microporous Mesoporous Mater. 93, 285 (2006); (b) M. C. Burleigh, M. A. Markowitz, S. Jayasundera, M. S. Spector, C. W. Thomas, and B. P. Gaber, J. Phys. Chem. B 107, 12628 (2003).

4. (a) D. Esquivel, E. De Canck, C. Jimenez-Sanchidrian, P. Van Der Voort, and F. J. Romero-Salguero, J. Mater. Chem. 21, 10990 (2011); (b) E. De Canck, I. Dosuna-Rodriguez, E. M. Gaigneaux, and P. Van der Voort, Materials 6, 3556 (2013).

5. (a) E. De Canck, L. Lapeire, J. De Clercq, F. Verpoort, and P. Van Der Voort, Langmuir 26, 10076 (2010); (b) E. De Canck, I. Ascoop, A. Sayari, and P. Van Der Voort, PCCP 15, 9792 (2013).

6. M. Ide, E. De Canck, I. Van Driessche, F. Lynen, and P. Van Der Voort, RSC Advances 5, 5546 (2015).

7. F. Goethals, I. Ciofi, O. Madia, K. Vanstreels, M. R. Baklanov, C. Detavernier, P. Van der Voort, and I. Van Driessche, J. Mater. Chem. 22, 8281 (2012).

8. S. Inagaki, O. Ohtani, Y. Goto, K. Okamoto, M. Ikai, K.-I. Yamanaka, T. Tani, and T. Okada, Angewandte Chemie-International Edition 48, 4042 (2009).

9. (a) S. Hudson, J. Cooney, B. K. Hodnett, and E. Magner, Chemistry of Materials 19, 2049 (2007); (b) E. Serra, E. Diez, I. Diaz, and R. M. Blanco, Microporous Mesoporous Mater. 132, 487 (2010); (c) Z. Zhou, R. N. K. Taylor, S. Kullmann, H. Bao, and M. Hartmann, Adv. Mater. 23, 2627 (2011).

10. (a) X. Wang, D. Lu, R. Austin, A. Agarwal, L. J. Mueller, Z. Liu, J. Wu, and P. Feng, Langmuir 23, 5735 (2007); (b) J. Wan, K. Qian, J. Zhang, F. Liu, Y. Wang, P. Yang, B. Liu, and C. Yu, Langmuir 26, 7444 (2010).

11. K. E. Uhrich, S. M. Cannizzaro, R. S. Langer, and K. M. Shakesheff, Chem. Rev. 99, 3181 (1999).

12. M. Vallet-Regi, A. Ramila, R. P. del Real, and J. Perez-Pariente, Chem. Mater. 13, 308 (2001).

13. (a) F. Ye, H. Guo, H. Zhang, and X. He, Acta Biomaterialia 6, 2212 (2010); (b) M. Vallet-Regi and E. Ruiz-Hernandez, Adv. Mater. 23, 5177 (2011).

14. (a) P. Horcajada, C. Serre, M. Vallet-Regi, M. Sebban, F. Taulelle, and G. Ferey, Angewandte Chemie-International Edition 45, 5974 (2006); (b) P. Horcajada, T. Chalati, C. Serre, B. Gillet, C. Sebrie, T. Baati, J. F. Eubank, D. Heurtaux, P. Clayette, C. Kreuz; J.-S. Chang, Y. K. Hwang, V. Marsaud, P.-N. Bories, L. Cynober, S. Gil, G. Ferey, P. Couvreur, and R. Gref, Nat. Mater. 9, 172 (2010).

15. M. Vallet-Regi, F. Balas, and D. Arcos, Angewandte ChemieInternational Edition 46, 7548 (2007).

16. R. Mellaerts, R. Mols, J. A. G. Jammaer, C. A. Aerts, P. Annaert, J. Van Humbeeck, G. Van den Mooter, P. Augustijns, and J. A. Martens, European Journal of Pharmaceutics and Biopharmaceutics 69, 223 (2008).

17. (a) J. Andersson, J. Rosenholm, S. Areva, and M. Linden, Chem. Mater. 16, 4160 (2004); (b) P. Horcajada, A. Ramila, J. PerezPariente, and M. Vallet-Regi, Microporous Mesoporous Mater. 68, 105 (2004).

18. S. W. Song, K. Hidajat, and S. Kawi, Langmuir 21, 9568 (2005).

19. I. Izquierdo-Barba, E. Sousa, J. Carlos Doadrio, A. Luis Doadrio, J. Perez Pariente, A. Martinez, F. Babonneau, and M. Vallet-Regi, J. Sol-Gel Sci. Technol. 50, 421 (2009).

20. C. X. Lin, S. Z. Qiao, C. Z. Yu, S. Ismadji, and G. Q. Lu, Microporous Mesoporous Mater. 117, 213 (2009).

21. H.-Y. Wu, F.-K. Shieh, H.-M. Kao, Y.-W. Chen, J. R. Deka, S.-H. Liao, and K. C. W. Wu, Chemistry-A European Journal 19, 6358 (2013).

22. (a) M. S. Moorthy, S.-S. Park, D. Fuping, S.-H. Hong, M. Selvaraj, and C.-S. Ha, J. Mater. Chem. 22, 9100 (2012); (b) M. S. Moorthy, J.-H. Bae, M.-J. Kim, S.-H. Kim, and C.-S. Ha, Particle and Particle Systems Characterization 30, 1044 (2013).

23. E. B. Cho and K. Char, Chem. Mater. 16, 270 (2004).

24. C. R. Kemnitz and M. J. Loewen, JACS 129, 2521 (2007).

Received: 29 January 2015. Accepted: 23 February 2015. 